\title{
A journey into Massimo Salvatores scientific work
}

\author{
Alain Zaetta ${ }^{*}$, Cyrille De Saint Jean ${ }^{* *}$, and Robert Jacqmin ${ }^{* * *}$ \\ CEA, CEA Nuclear Energy Division, 13108, Saint-Paul-Lez-Durance, FR
}

Received: 24 February 2021 / Received in final form: 12 March 2021 / Accepted: 29 April 2021

\begin{abstract}
Massimo SALVATORES was not the man of a country, an organization, or a team. Certainly because of his origin, his education, and his culture, Massimo has always favored a broader and more open collaboration instead of a bureaucratic and shortsighted approach to the research, keeping the achievements only to a restricted inner circle. He was convinced that disinterested sharing makes one stronger and Massimo is one of the few nuclear reactor physicists who elevated international collaboration to its highest level. A short history of the major contributions that Massimo made to his dear discipline, Neutronics, will emphasize this peculiar aspect of his career.
\end{abstract}

It all started in Italy, at the University of Turin. Massimo was passionate about nuclear physics and in particular nuclear reactors physics $[1,2,3]$. He immediately saw the strength and potential of the perturbation method for calculating the behavior of nuclear reactor cores [4-7]. Throughout his career he has continuously developed this technique and broadened its field of application.

When Massimo joined the CEA in 1977, fast neutron reactors were under strong development in all the major industrial countries. In France, the PHENIX reactor was operational and at the same time, the SUPER-PHENIX project was under way. From the reactor physics point of view, at that time the nuclear data knowledge was the major scientific challenge. He understood that the required accuracy for reactors could be achieved only by relying on integral measurements, in addition to differential nuclear data measurements [8-11]. By combining the exceptional contribution of the integral measurements carried out in the MASURCA reactor at CEA-Cadarache and its knowhow in mathematical perturbation techniques, Massimo helped in establishing an adjusted nuclear data set that would meet the required accuracy needed by the SUPERPHENIX project [12].

The development of Fast Reactors has always benefited from intense and broad international collaboration. From the start, USA shared their knowledge in this field with the other industrialized countries engaged in this adventure. In addition, bilateral Franco-Russian (Soviet at that time) collaboration was started and is still active today. At

\footnotetext{
* e-mail: alainzaetta@free.fr

** e-mail: cyrille.de-saint-jean@cea.fr

*** e-mail: robert.jacqmin@cea.fr
}

European level, the collaboration was even closer. If on the industrial level SUPER-PHENIX was designed and built by France, Germany, Italy and the Benelux, the supporting experimental R\&D was not left out, since Great Britain, Germany and France each had built and exploited a critical mock-up reactor very close to each other, thus facilitating not only the sharing of knowledge but also the better use of scarce fuels materials available at that time. During this prosperous period of activity, Massimo was able to forge a strong and wide network of partnerships and friendships.

The feedback from the divergence and operation of SUPER-PHENIX, the most powerful Fast Reactor ever built, has been very rich for reactor physics [13,14]. Massimo, with his international aura and as head of the reactor physics and fuel cycle section, brought together an international team of more than ten people permanently in CEA-Cadarache to analyze the results obtained. Two major results can be highlighted: the predictive capacity of the developed methods, related codes, and nuclear data for calculating the reactivity of the reactor core was confirmed, while the calculation of the control rods worth exhibited discrepancies when compared to measurements. This discrepancy motivated the extension of an experimental program (BALZAC $[15,16])$ in the MASURCA zero-power reactor and refinements in calculation methods and schemes $[17,18]$.

The OECD Nuclear Energy Agency (NEA) has always played a major role through its fundamental mission of facilitating international collaboration. Its nuclear science committee and the Data Bank, well beyond a mere forum for discussion, have enabled essential tangible achievements. The nuclear data activities carried out under the NEA sponsorship are an emblematic example of these 
achievements. Since the 1960s, the NEA has provided the framework for progress in this field and has continued its role until today by developing and distributing to the entire scientific community the only existing international nuclear data base: the JEFF nuclear data library [19]. Massimo, guided by his mentor Jacques Bouchard, aware of the strength and essential role of the NEA, has been heavily involved in the work of the NEA, without interruption for nearly 40 years. Because of his role as chairman of the Science Committee or of the JEFF project, he earned such respect, prestige and notoriety that many actual international collaborations were established from and thanks to the NEA. In addition, he participated in several expertise and scientific evaluation committees for the Paul Scherrer Institute in Switzerland or for the IRMM, which focus is in measurements of nuclear data in Belgium.

Fast Reactors development is an eternal succession of missed opportunities. The shortage of uranium expected at the end of the last century did not occur, for lack of a worldwide deployment of nuclear energy, based on water reactors, handicapped by the Chernobyl accident which encouraged many countries to refuse the contribution of nuclear power or reduce its importance. The nuclear renaissance glimpsed at the start of the 2000s collapsed under the double blow of the global financial crisis and the Fukushima accident in Japan, rejecting much later the need to use Fast Reactors and leading France to stop the ASTRID project.

Thus, in the last 20th century decade, the capacity of the Fast Reactors for plutonium breeding (as SUPERPHENIX) appeared no longer necessary. Nevertheless, a double question arose: how to manage the excess plutonium produced by existing nuclear reactors, and at the same time how to reduce the quantity of nuclear waste in order to increase the acceptability of their storage?

To the first question, the partial recycling of $\mathrm{Pu}$ in existing water reactors was a response implemented in several countries, including France. In addition, showing the flexibility of Fast Reactors to adapt to this new context by being able to consume plutonium was a new challenge. Massimo ensured the initial thoughts in this area, which led to the launch of the CAPRA project [20] and subsequently assumed the technical coordination, in particular its international aspect.

Regarding the second question, the solution of nuclear waste disposal raised such societal opposition both in France and abroad, that the French political authorities decreed a pause in the actual implementation of this solution and launched (through the so-called 1991 Bataille act), three axes of research on nuclear wastes in order to reduce their impact and facilitate their public acceptance. The third axis aimed to explore scientific and technical ways to destroy long-lived and high activity waste. Again, Massimo played a central role in this endeavor [21-23]. On the one hand, he federated national efforts by ensuring the co-presidency with Jean-Paul Schapira (CNRS) of the research group, created for this purpose, called GEDEON for the Management of Nuclear Waste through New Options, bringing together CEA, CNRS, EDF and FRAMATOME. On the other hand, within CEA, he promoted accelerator-driven systems (ADS), through the
MUSE experimental program in MASURCA [24-26] (and the associated European collaboration [27-30]) and launched the SPIN project for Separation and Incineration, which enabled an integrated interdisciplinary approach bringing together skills in both chemistry and physics. For many of its participants, this program remains a model of what CEA can and must provide, in addition to having been a wonderful human adventure due in large part to the human qualities of its leaders Madame Viala and Massimo.

More recently in the 2000s, in the context of the nuclear renaissance, the need to use fast neutron reactors was once again compelling. In order to federate international efforts in terms of development of this technology, B. Magwood and J. Bouchard jointly took the initiative to create the "Generation IV" Forum with the aim of proposing concepts of reactors most suited to meeting new requirements for nuclear energy in terms of safety, economy of natural resources, and nuclear waste management. Once again Massimo found himself at the heart of the scientific concerns by assuming the technical direction of the Forum [31,32].

For a large fraction of his career, Massimo was also involved in the education and training of young physicists. For about 20 years, he gave advance graduate-level lectures on Reactor Physics and Shielding. He was also the thesis director of many PhD students. In 1995, he created the Frédéric Joliot Summer School in Reactor Physics. This Summer School has had considerable success from its start, and is still running today.

Even after his official retirement from CEA, Massimo continued to work for the collective good. While he remained active in France, as an advisor to the Director of Nuclear Energy of CEA, he invested himself in new activities directly with the FZK research center in Karlsruhe and with the American National Laboratories of ANL and INL [11,33]. In addition, he initiated several WPEC (Working Party on International Nuclear Data Evaluation Co-operation) sub-groups at the NEA mainly related to integral measurements and their use in nuclear data knowledge [34-39].

On a very personal level, one day Massimo told me when speaking of Enrico Fermi that we were nothing, but dwarves perched on the shoulders of giants such as this glorious Italian who immigrated to the USA. Today with the disappearance of Massimo we feel a great void, we are like orphans ... we have lost our giant.

Massimo's major contribution to the advancement of reactor physics has been recognized by all. He has received numerous awards and distinctions, the most prestigious of which are the Grand Prix Ampère awarded by the French Academy of Sciences and the E. Wigner Award awarded by the American Nuclear Society [40].

\section{References}

1. M. Salvatores et al., ZPR-6 initial plate-rod heterogeneity measurements, Trans. Am. Nucl. Soc. 14, 18 (1971)

2. B.A. Zolotar, M. Salvatores, B.M. Bingman, E.E. Lewis, A comparative study of heterogeneity treatments for ZPR plate cells, Trans. Am. Nucl. Soc. 14, 848 (1971) 
3. P.H. Kier, M. Salvatores, The effect of local flux distortions on the Doppler effect of small fissile samples, Nucl. Sci. Eng. 53, 479-482 (1974)

4. G.P. Cecchini, M. Salvatores, Advances in the generalized perturbation theory, Nucl. Sci. Eng. 46, 304-309 (1971)

5. M. Salvatores, Adjustment of multigroup neutron cross sections by a correlation method, Nucl. Sci. Eng. 50, 345-353 (1973)

6. A. Gandini, G. Palmiotti, M. Salvatores, Equivalent generalized perturbation theory (EGPT), Ann. Nucl. Energy 13, 109-114 (1986)

7. A. Gandini, M. Salvatores, L. Tondinelli, New developments in generalized perturbation methods in the nuclide field, Nucl. Sci. Eng. 62, 339-345 (1977)

8. A. Gandini, M. Salvatores, Nuclear data and integral measurements correlation for fast reactors-part 3 : the consistent method, RT/FI(74)3, ComitatoNazionale per l'Energia Nucleare, Rome (1974)

9. A. D'Angelo, A. Oliva, G. Palmiotti, M. Salvatores, S. Zero, Consistent utilization of shielding benchmark experiments, Nucl. Sci. Eng. 65, 477-491 (1978)

10. M. Salvatores, G. Aliberti, G. Palmiotti, The role of differential and integral experiments to meet requirements for improved nuclear data, in: ND 200\%: International Conference on Nuclear Data for Science and Technology, 22-27 April, Nice, France, Vol. 2, pp. 883-886, 2008

11. G. Youinou, R. Vondrasek, H. Veselka, M. Salvatores, M. Paul, R. Pardo, G. Palmiotti, T. Palchan, O. Nusair, J. Nimmagadda, C. Nair, P. Murray, T. Maddock, S. Kondrashev, F.G. Kondev, W. Jones, G. Imel, C. Glass, J. Fonnesbeck, J. Berg, W. Bauder, MANTRA: an integral reactor physics experiment to infer actinide the neutron capture cross sections of actinides and fission products in fast and epithermal spectra, Nucl. Data Sheets 119, 169-172 (2014)

12. G. Palmiotti, M. Salvatores, Use of integral experiments in the assessment of large liquid-metal fast breeder reactor basic design parameters, Nucl. Sci. Eng. 87, 333-348 (1984)

13. M. Salvatores et al., A First Analysis of Selected Neutronics Experiments at Superphénix1 Start-up, in: International Topical Meeting on Advances in Reactor Physics, Mathematics and Computation, Paris, France, April 1987

14. M. Salvatores, M. Carta, R. Soule, Power reactor and critical experiment heterogeneity effects assessment for bias factors definition, Nucl. Sci. Eng. 100, 1-15 (1988)

15. R. Soule, G. Palmiotti et al., The BALZAC Program on the MASURCA Critical Facility Main Result, in: International Reactor Physics Conference, Jackson Hole, Wyoming, September 1988

16. J.C. Gauthier, J.C. Cabrillat, G. Palmiotti, M. Salvatores, M. Giese, M. Carta, J.P. West, Measurement and predictions of control rod worth, Nucl. Sci. Eng. 106, 18-29 (1990)

17. M. Carta, G. Granget, G. Palmiotti, M. Salvatores, R. Soule, Control rod heterogeneity effects in liquid-metal fast breeder reactors: method developments and experimental validation, Nucl. Sci. Eng. 100, 269-276 (1988)

18. R. Soule, G. Granger, J.C. Gauthier, J.C. Cabrillat, M. Martini, G. Palmiotti, M. Salvatores, D. Calamand, A. D'Angelo, The BALZAC program: summary of the comparison between the main calculated and experimental results, in: PHYSOR-90 International Conference on the Physics of Reactors, Marseille, France, 23-27 April 1990
19. A.J.M. Plompen, O. Cabellos, C. De Saint Jean, M. Fleming, A. Algora, M. Angelone, P. Archier, E. Bauge, O. Bersillon, A. Blokhin, F. Cantargi, A. Chebboubi, C. Diez, H. Duarte, E. Dupont, J. Dyrda, B. Erasmus, L. Fiorito, U. Fischer, D. Flammini, D. Foligno, M.R. Gilbert, J.R. Granada, W. Haeck, F.-J. Hambsch, P. Helgesson, S. Hilaire, I. Hill, M. Hursin, R. Ichou, R. Jacqmin, B. Jansky, C. Jouanne, M.A. Kellett, D.H. Kim, H.I. Kim, I. Kodeli, A.J. Koning, A. Yu. Konobeyev, S. Kopecky, B. Kos, A. Krása, L.C. Leal, N. Leclaire, P. Leconte, Y.O. Lee, H. Leeb, O. Litaize, M. Majerle, J.I. Márquez Damián, F. Michel-Sendis, R.W. Mills, B. Morillon, G. Noguère, M. Pecchia, S. Pelloni, P. Pereslavtsev, R.J. Perry, D. Rochman, A. Röhrmoser, P. Romain et al., The joint evaluated fission and fusion nuclear data library, JEFF-3.3, Eur. Phys. J. A 56, 181 (2020)

20. A. Vasile, G. Vambenepe, J.C. Lefevre, K. Hesketh, W. Maschek, Ch. De Raedt, D. Haas, The CAPRA - CADRA Programme, ICONE 8, 2-6 April 2000, Baltimore, MD USA

21. C. Prunier, M. Salvatores, J.F. Babelot, J. van Geel et al., Target development and transmutation experiments in the frame of the EFTTRA European collaboration, in: International Topical Conference on the Evaluation of Fuel Cycle for Future Nuclear Systems GLOBAL'95, Versailles, France, 11-14 September 1995

22. M. Salvatores, I. Slessarev, M. Uematsu, A global physics approach to transmutation of radioactive nuclei, Nucl. Sci. Eng. 116, 1-18 (1994)

23. G. Palmiotti, G. Aliberti, M. Salvatores, J. Tommasi, Integral experiments analysis for validation and improvement of minor actinide data for transmutation needs, in: Proceedings of the International Conference on Nuclear Data for Science and Technology, pp. 1436-1441, Santa Fe, 2005

24. M. Salvatores, M. Martini, I. Slessarev, J.C. Cabrillat, J.P. Chauvin, P. Finck, R. Jacqmin, R. Soule, A. Tchistiakov, MUSE-1: a first experiment at MASURCA to validate the physics of sub-critical multiplying systems relevant to ADS, in: Second International Conference on Accelerator-Driven Transmutation Technologies and Applications, Kalmar, Sweden, 3-7 June, 1996

25. M. Salvatores, M. Martini, I. Slessarev, J.C. Cabrillat, J.P. Chauvin, P. Finck, R. Jacqmin, R. Soule, A. Tchistiakov, The neutronics of a source-driven multiplying medium and its experimental validation at MASURCA, in: Physor 96 International Conference on the Physics of Reactors, Mito, Japan, 16-20 September 1996

26. R. Soule, M. Salvatores, R. Jacqmin, M. Martini, J.F. Lebrat, P. Bertrand, U. Broccoli, V. Peluso, Validation of neutronic methods applied to the analysis of fast subcritical systems: The MUSE-2 experiments, Global'97, Yokohama, Japan, 5-10 October 1997

27. C. Rubbia, S. Monti, M. Salvatores, A. D'Angelo, G. Bignan, N. Burgio, D. Cacuci, J. Cahalan, M. Carta, P. Fougeras, G. Granget, G. Imel, C. Jammes, Y. Kadi, J. Knebel, S. Maloy, D.G. Naberejnev, H. Philibert, P. Ravetto, TRADE: a full experimental validation of the ADS concept in a European perspective, in: Proceedings of the International Meeting on Nuclear Applications of Accelerator Technology: Accelerator Application in a Nuclear Renaissance, pp. 8-16, San Diego, 2003 
28. P. Agostini, A. Aiello, P. Turroni, F. Pisacane, S. Monti, S. Buono, L. Maciocco, S. Maloy, Y. Lejeail, M. Salvatores, The TRADE target design and development, in: Proceedings of the International Meeting on Nuclear Applications of Accelerator Technology: Accelerator Application in a Nuclear Renaissance, pp. 103-108, San Diego, 2003

29. G. Aliberti, G. Imel, G. Palmiotti, M. Salvatores, C. Jammes, G. Perret, Dynamic analysis of source driven fast neutron systems for experimental techniques of subcritical reactivity measurement, Trans. Am. Nucl. Soc. 89, 641 (2003)

30. C. Rubbia, M. Carta, N. Burgio, C. Ciavola, A. D'Angelo, A. Dodaro, A. Festinesi, S. Monti, A. Santagata, F. Troiani, M. Salvatores, M. Delpech, Y. Kadi, S. Buono, A. Ferrari, A.H. Martínez, L. Zanini, G. Imel, Neutronic analyses of the TRADE demonstration facility, Nucl. Sci. Eng. 148, 103-123 (2004)

31. 2009 GIF Symposium Proceedings, Paris (France) - 9-10 September, 2009, ISBN 978-92-64-99115-6

32. J. Bouchard, M. Salvatores, Reactor physics development from the early sixties to yesterday: John Rowlands contribution, Trans. Am. Nucl. Soc. 107, 1171-1172 (2012)

33. G. Youinou, G. Palmiotti, C. Mcgrath, G. Imel, M. Pau, R. Pardo, F. Kondev, M. Salvatores, MANTRA: an integral reactor physics experiment to infer actinide capture crosssections from thorium to californium with accelerator mass spectrometry, J. Korean Phys. Soc. 59, 1940-1944 (2011)

34. G. Palmiotti, M. Salvatores, The role of experiments and of sensitivity analysis in simulation validation strategies with emphasis on reactor physics, Ann. Nucl. Energy 52, 10-21 (2013)
35. M. Salvatores, G. Palmiotti, G. Aliberti, P. Archier, C. De Saint Jean, E. Dupont, M. Herman, M. Ishikawa, T. Ivanova, E. Ivanov, S.-J. Kim, I. Kodeli, G. Manturov, R. McKnight, S. Pelloni, C. Perfetti, A.J.M. Plompen, B.T. Rearden, D. Rochman, K. Sugino, A. Trkov, W. Wang, H. Wu, W.-S. Yang, Methods and issues for the combined use of integral experiments and covariance data: results of a NEA international collaborative study, Nucl. Data Sheets 118, 38-71 (2014)

36. G. Palmiotti, M. Salvatores, G. Aliberti, M. Herman, S.D. Hoblit, R.D. McKnight, P. Obložinský, P. Talou, G.M. Hale, H. Hiruta, T. Kawano, C.M. Mattoon, G.P.A. Nobre, A. Palumbo, M. Pigni, M.E. Rising, W.-S. Yang, A.C. Kahler, Combined use of integral experiments and covariance data, Nucl. Data Sheets 118, 596-636 (2014)

37. M. Salvatores et al., OECD/NEA WPEC Subgroup 26 Final Report, Uncertainty and Target Accuracy Assessment for Innovative Systems Using Recent Covariance Data Evaluations, Nuclear Science NEA/WPEC-26 (2008)

38. M. Salvatores, G. Palmiotti, Methods and approaches to provide feedback from nuclear and covariance data adjustment for improvement of nuclear data files: major findings of the NEA WPEC Subgroup 39, ND2019, Beijing, China, 2019. (to appear on EPJ Web of Conference)

39. G. Palmiotti, M. Salvatores, Revisiting the bias factor methodologies for the validation of fast test reactors, Ann. Nucl. Energy 145, 107591 (2020)

40. M. Salvatores, The interplay of theory and experiments in reactor physics, Invited lecture as Eugene P. Wigner Reactor Physicist Award Winner, Trans. Am. Nucl. Soc. 93, 361-362 (2005)

Cite this article as: Alain Zaetta, Cyrille De Saint Jean, Robert Jacqmin, A journey into Massimo Salvatores scientific work, EPJ Nuclear Sci. Technol. 7, E1 (2021) 